\title{
Ethical and Medical Dilemmas of Space Tourism ${ }^{1}$
}

\author{
Melinda Marsh
}

\section{Introduction}

With every new business come new ethical considerations, particularly in groundbreaking industries where no current regulations exist. Even in industries that are well established, there are grey areas separating the minimum required by law and what is ethically responsible. If a company does not provide the minimum facilities required by law, the regulating agencies can fine them. If a company does meet its legal requirements but does not surpass them, that company risks litigation, or at least bad publicity. Conversely, a company that adopts excessively ethical behaviors can face far higher startup cost, although their caution could be work out to be cheaper in the longer term.

In the fledgling field of space tourism, new companies are being confronted with major problems relating to the current lack of industry regulations. Since there are no regulating bodies, CEOs who do not have a strong personal code of ethics may be tempted to cut corners and hope for the best. This is an unwise decision given the space tourism industry's potential for disaster. What if a private-sector Challenger or Columbia disaster occurred? What if SpaceShipOne had exploded or crashed while it was on one of its X-prize flights? An explosion caught live on television would certainly spell doom for the space tourism industry, as it would no doubt severely reduce the enthusiasm of the 35-80\% of people who claim they would like to go into space one day (2002). Likewise, it would reinforce the fears of those whose prime concern is safety (Berinstein, 2002).

\footnotetext{
${ }^{1}$ This paper is the pre-print version of the following article: Marsh, M. S. (2006). Ethical and Medical Dilemmas of Space Tourism. Advances in Space Research, 37(9), 1823-1827 and published by Elsevier Limited. According to Elsevier Limited (permission request 500508582), authors have the right to post pre-print copies to the internet. The print version of this article is copyrighted by Elsevier Limited.
} 
Space hotels are another fledgling industry that may very well suffer due to the current blur between ethics and legality, as "space hotel" regulations are neither well designed nor well developed at this stage. This is unfortunate since safety and medical guidelines should be of paramount importance due to the extreme nature of space travel. It is therefore difficult to imagine what is likely to be the minimum legal requirements for safe travel from a biomedical standpoint. In order to provide an experience that is enjoyable as well as safe, various medical dilemmas need to be considered, such as what to do in the event of a medical emergency, and the general disclosures that should be provided because of possible physiological changes due to microgravity. The information that follows is of particular interest to start up space businesses which will require more risk acceptance on the part of the tourists. As space tourism becomes more commonplace and more studies are performed, it is likely that the risks will be better understood and mature space businesses may not need to worry as much about the risks to their customers.

\section{Medical Emergencies}

All transportation systems, regardless of their type, must provide medical treatment in the event of an emergency. While there are currently no international regulations listing liabilities for a space business if medical care is not provided, there are conventions listing other transportation systems' liabilities that can be used as a framework in the event of passenger death or injury. The " Convention for the Unification of Certain Rules Relating to International Carriage by Air'” (Warsaw Convention) declares an airline liable... 
...for damage sustained in the event of the death or wounding of a passenger or any other bodily injury suffered by a passenger, if the accident which caused the damage so sustained took place on board the aircraft or in the course of any of the operations of embarking or disembarking. (Convention for the Unification of Certain Rules Relating to International Carriage by Air (Warsaw Convention), 1929, Article 17).

Similarly, cruise ship companies have the " Athens Convention relating to the Carriage of Passengers and their Luggage by Sea’’ which declares: The carrier shall be liable for the damage suffered as a result of the death of or personal injury to a passenger.

...if the incident which caused the damage so suffered occurred in the course of the carriage and was due to the fault or neglect of the carrier or of his servants or agents acting within the scope of their employment. (Athens Convention relating to the Carriage of Passengers and their Luggage by Sea, 1974, Article 3).

Neither of these treaties specifies the minimum (if any) medical facilities that must be on board, however in the event of a medical emergency such as a heart attack, a carrier could be sued for neglecting to have the resources necessary to save the passenger. In the flight crew guidelines set forth by the Office of the Associate Administrator for Commercial Space Transportation (AST) branch of the Federal Aviation Administration (FAA), requires all flight crew to be able to operate the vehicle in the event of an emergency (in Section 6c) but it does not list recommendations for emergency medical training and does not suggest that this would be needed probably due to the short duration of suborbital flights (Federal Aviation Administration, 2005a). In the absence of legal regulations covering space tourism, companies in the business should consider make reasonable medical support facilities available, if only for ethical reasons. The International Space Station (ISS) provides a good example with what they offer 
orbiting commercial enterprises. Two members on board each shuttle mission, as well as both members of each ISS expedition crew, are designated and trained as crew medical officers (CMOs), and are responsible for providing medical treatment on board (Williams, 2003). While they are not required to be medical doctors, they are trained in how to operate the medical facilities available to them. On the ISS, the crew have a number of medical facilities; for example, an advanced life support pack, medical restraints, a protection kit in the event of toxic contamination, an ultrasound, a defibrillator, and an emergency respiratory support pack for stabilization prior to emergency transportation back to Earth (Williams, 2003). Through radio and video communications, CMOs have the support of an entire medical support team back on Earth, including physicians, biomedical engineers, IT specialists, nurses, and a flight surgeon (Messerschmid et al., 2004).

In the first 89 shuttle missions, over 1777 separate medical events were reported, including 141 injuries, and of course the seven fatalities of the Challenger accident (Williams, 2003). It would be foolish to assume that there would be fewer medical events involving space tourists. Given the high possibility of a medical event, it clearly would be advisable for any space tourism company doing more than suborbital flights to have similar facilities to the ISS, as well as a physician on call for telemedical consultations. Further, if commercial space flights increase in frequency, there is a strong likelihood that events will occur in which return to Earth is impossible, and therefore it would be advisable to establish a remote hospital such as the one being designed for a future Mars base. The Mars base will provide one or two medical doctors in the crew, as well as adequate medical facilities including diagnostic equipment, surgical facilities, ICU, 
sterilization and transfusion equipment, and long-lasting medicines in various forms (IV, oral, and nasal versions) which will enable the treatment of a wide range of conditions (Kozlovskaya and Egorov, 2003).

\section{Health Risks}

Although the medical facilities described above would, one hopes, reduce the likelihood of passenger deaths, a space business should nevertheless disclose the health risks involved in space travel, which include the loss of bone density due to the loss of calcium, decreased muscle strength, decreased blood plasma, decreased cardiovascular efficiency, increased risk of kidney stones, increased exposure to radiation, and immune system suppression (Williams, 2003). These health risks can lead to the increased likelihood of cancer, osteoporosis, and space motion sickness. Written disclosure should include

...the known hazards and risks associated with a mission, and should include nominal and non-nominal launch operations. The RLV operator should describe these hazards and risks in a manner that is understandable to the space flight participant. This description should include the likelihood and consequences of any reasonably foreseeable hazardous event and safety-critical system failures that could result in a serious injury or death to the space flight participant. The RLV operator should inform any space flight participant that the space flight may result in his or her death, serious injury, disability, and total or partial loss of physical and mental function (Federal Aviation Administration, 2005b, Section 6A1).

An additional disclosure might be necessary for passengers who are taking prescription drugs. Drugs react differently when taken in a microgravity environment

(Williams, 2003), and so passengers should be urged to consult their doctor prior to taking a trip to find out if the risks warrant curtailing their drug regime in the meantime. A doctor specializing in aerospace medicine should be available to the patient's primary 
physician for consultation on the drugs' potential side effects in microgravity. In fact, any space business that is serious about protecting the lives of its passengers would require a medical report prior to issuing a ticket, just as NASA requires a strict medical examination prior to its astronaut selection.

At present, the current laws do not require a medical examination for space tourists, although the Commercial Space Launch Amendment Act of 2004 does provide for the possibility of mandatory medical examinations for space tourists. Already, the AST branch of the FAA requires flight crews to obtain a 2nd class medical certificate for short duration suborbital flights in the FAA's Flight Crew Guidelines (2005a) Section 6.b and does not provide guidelines for longer duration flights. The FAA's Space Flight Participants Guidelines (2005b) does not require mandatory medical exams for passengers, Section 8 states detailed medical examinations would be made at the discretion of a physician trained in aerospace medicine. Regardless of the minimum legal requirements, given the inherent risks of space travel, it would be advisable for a carrier to set minimum health guidelines for its passengers, with a stricter version for its crew as both passengers and crew need to be able to survive the trip with minimal long- and short-term health problems.

Due to the stresses experienced by the body, people suffering from certain conditions should avoid space travel altogether. These include back and neck problems, compromised immune system, heart problems - especially abnormally high heart rates and high blood pressure, psychiatric disorders, and chronic dehydration. The primary reason for prohibiting those with back and neck problems is the stress of reentry. A poor heart condition could be exasperated by the inevitable increase in blood pressure, which 
sets in approximately $6 \mathrm{~h}$ after exposure to microgravity. During this time, the heart rate will also change, although how it will be affected can vary. The differences between astronauts' heart rate pre-launch and in orbit have ranged from a two-beat-per-minute decrease to an eleven beat- per-minute increase. Upon re-exposure to the Earth's gravity, the average heart rate of an astronaut is anywhere from 13 to 66 beats a minute over their baseline (Bullard, 1972). Due to microgravity, the blood in one's body goes through a redistribution process as the brain senses that there is too much blood in the body and works to remove it. Within the first $24-48 \mathrm{~h}$, approximately $500 \mathrm{ml}$ of blood is lost through urination, leading to dehydration (Bullard, 1972).

\subsection{Reentry}

Space tourists must be made aware of the possibility of dehydration and dizziness

upon reentry (Bullard, 1972). From the moment that the spacecraft touches down, medical staff need to be immediately available for the passengers and crew, who ideally should be kept under observation for several days after reentry. It took the crew of the Soyuz 9 approximately 10 days before their posture and walking ability returned to normal (Bullard, 1972).

\section{Additional Medical Concerns}

\subsection{Space Sickness}

Shortly after the arrival of astronauts into space, most suffer a syndrome called “Space Adaptation Sickness”, This is similar to the motion sickness suffered by passengers on airlines, and is caused by disorientation and the brain's inability to 
reconcile what it is experiencing and the sensation of orientation provided by the inner ear. Various different sensory perceptions lead to dizziness, nausea, and vomiting, however most of the symptoms of space sickness can be reduced with anti-nausea pills, and all will usually subside completely within a few days as the body adapts to microgravity (Bullard, 1972).

Passengers worried about nausea would be well advised to speak with their primary-care physician, because it would not be ethical for a doctor who does not know the complete medical history of the patient to recommend or prescribe anti-space sickness pills due to the risk of pharmacological interaction. Clearly the most ethical stance a space tourism business could take is to provide information to the primary-care physician. If the primary-care physician chooses to medicate a patient, then that physician must take responsibility for any eventuality. The space tourism business, nevertheless, can and should remind passengers to take their pills prior to the onset of nausea, and they should provide passengers with water. For passengers who choose not to take anti-nausea pills, space sickness bags will need to be provided.

\subsection{Loss of Bone Density}

Due to the reduction in bone density as well as the decrease in cardiovascular fitness, some form of mandatory exercise program should be implemented during the space flight. While it would be easy to mandate exercise regimes for the crew, it might be more difficult to get passengers to comply. Nevertheless, daily exercise slows the loss of bone density and retards the loss of cardiovascular efficiency. Space businesses should therefore disclose the additional health risks involved if passengers do not exercise, 
including the tremendous discomfort they are likely to experience on their return to Earth due to weakened muscles.

Again, we must turn to US and Russian space programs for advice. On the Russian Mir space station, $2.5 \mathrm{~h}$ of daily resistance exercises were required (Convertino, 2002). The US has slowly increased its exercise program from 30 min a day in the early flights to around $2 \mathrm{~h}$ each day in 2004 (Convertino, 2002). The exercises carried out on board the Mir required 1400 kcal per day, which was roughly $1 / 3$ to $1 / 2$ of the cosmonauts’ daily calorie intake (Convertino, 2002).

Although the exercise equipment on board the space craft should be designed to minimize potential injury, accidents will inevitably occur, hence medically trained members of the crew should be prepared to treat overworked muscles and any other such injuries. There also needs to be provisions for cleaning the exercise equipment. In a normal gym, it is considered common courtesy to wipe off equipment after you have used it to prevent creating a breeding ground for bacteria. This is also vital in space as bacterial growth increases in microgravity due to decreased generation times (Nickerson et al., 2003).

\subsection{Diseases}

Due to the problems of immune suppression and the increased rate of bacterial growth, the prevention of disease becomes a real problem. Legally, the most important thing space businesses can do is disclose the increased risk of disease in microgravity. They should also attempt to reduce the risk of disease by regularly wiping all surfaces, floors, and ceilings with disinfectant. If there is any chance that bodily fluids (urine, 
sweat, blood, feces, semen, saliva, etc.) have come in contact with a surface, that surface should be sterilized. Even so, there will be additional risks due to the increasing virulence of bacteria or other pathogens.

\subsection{Sex and Pregnancy in space}

In a space hotel, sex and eventually a conception could occur in microgravity. If this is the case, would the hotel be obliged to provide adequate facilities for sexual recreation? On Earth, a hotel's primary purpose is to provide a place to sleep although other activities do occur. The hotel is not responsible for STDs or pregnancies that occur on their premises. However, a space facility by its very nature is in an extreme environment, and information on human pregnancy in microgravity is nonexistent.

There have been studies of fetal development in rats in microgravity, and utilizing that information we can guess what would happen in a human pregnancy (Sekulic et al., 2005). Microgravity hinders neither the conception nor embryogenesis (the cellular differentiation that leads to an embryo) (Sekulic et al., 2005). In fact, up until 21 weeks gestational age a human fetus is in an environment similar to microgravity. However, if the rats are any indication, once past the 26th week of pregnancy, the lack of gravity is likely to lead to atrophy of the muscles in the lower back, the lower extremities, and the left ventricle of the fetus (Sekulic et al., 2005). On return to a $1 \mathrm{~g}$ environment, many of the rat pups that were conceived in microgravity lost weight and many more died in first week of life when compared to a control group. These results were statistically significant. 
For passengers, the possible risks related to pregnancy should be disclosed. While a space business can recommend that its passengers refrain from sex, it is not logical to assume that birth control can be forced on passengers that do not wish to use it, nor can any space hotel guarantee the usage or success of condoms. Accordingly, all potential risks should be listed in the disclosures provided by the hotel.

\section{Conclusion}

Space is a dangerous environment and the legal minimums required for space tourism have yet to be established. If a business is to operate ethically in space, first it has to establish what the dangers are and what its liabilities might be. Since space tourism is largely unregulated at present, companies would be well advised to consider the liabilities of other tourism areas and strive to surpass their minimums to ensure the safety of their passengers. Provided that passengers are aware of the risks and provided companies act ethically and attempt to reduce those risks above and beyond their minimum legal requirements, it is likely that participants in the space tourism industry will enjoy a profitable and exciting future.

\section{References}

Athens Convention relating to the Carriage of Passengers and their Luggage by Sea. Retrieved Dec 6, 2004, from <http://www.admiraltylawguide. com/conven/passengers1974.html/>, 1974.

Berinstein, P. Making space happen: private space ventures and the visionaries behind them. Plexus, Medford, NJ, 2002. 
Bullard, R.W. Physiological problems of space travel. Annu. Rev. Physiol. 34, 205-234, 1972.

Convention for the Unification of Certain Rules Relating to International Carriage by Air (Warsaw Convention). Retrieved Dec 6, 2004, from <http://www.forwarderlaw.com/archive/warsaw.htm/>, 1929.

Convertino, V.A. Planning strategies for development of effective exercise and nutrition countermeasures for long-duration space flight. Nutrition 18 (10), 880-888, 2002.

Federal Aviation Administration. Draft Guidelines for Commercial Suborbital Reusable Launch Vehicle Operations with Flight Crew. Washington, DC: Federal Aviation Administration, 2005a.

Federal Aviation Administration. Draft Guidelines for Commercial Suborbital Reusable Launch Vehicle Operations with Space Flight Participants. Washington, DC: Federal Aviation Administration, 2005b.

Kozlovskaya, I.B., Egorov, A.D. Some approaches to medical support Martian expedition. Acta Astronaut. 53 (4-10), 269-275, 2003. Messerschmid, E., Haignere, J.-P., Damian, K., Damann, V. The European astronaut centre prepares for international space station operations. Acta Astronaut. 54 (7), 527-539, 2004.

Nickerson, C.A., Ott, C.M., Wilson, J.W., Ramamurthy, R., LeBlanc, C.L., Honer zu Bentrup, K., et al. Low-shear modeled microgravity: a global 
environmental regulatory signal affecting bacterial gene expression, physiology, and pathogenesis. J. Microbiol. Methods 54 (1), 1-11, 2003.

Sekulic, S.R., Lukac, D.D., Naumovic, N.M. The fetus cannot exercise

like an astronaut: gravity loading is necessary for the physiological

development during second half of pregnancy. Med. Hypotheses 64

(2), 221-228, 2005.

Williams, D.R. The biomedical challenges of space flight. Annu. Rev.

Med. 54 (1), 245-256, 2003. 